framum

Sociológico

\section{Forum Sociológico}

Série II

32 | 2018

Fraturas sociais e educativas: Desafios para a sociologia da educação

\title{
A escola como demanda social complexa : Envolvimentos escolares e motivos das ocupações das escolas públicas secundárias do Rio de Janeiro em 2016
}

School as a complex social demand: School involvements and motives of public secondary schools occupations in Rio de Janeiro in 2016

Ubirajara Santiago de Carvalho Pinto

\section{(2) OpenEdition}

Journals

Edição electrónica

URL: https://journals.openedition.org/sociologico/2019

DOI: 10.4000/sociologico.2019

ISSN: 2182-7427

Editora

CICS.NOVA - Centro Interdisciplinar de Ciências Sociais da Universidade Nova de Lisboa

Edição impressa

Paginação: 39-47

ISSN: 0872-8380

Refêrencia eletrónica

Ubirajara Santiago de Carvalho Pinto, «A escola como demanda social complexa : Envolvimentos escolares e motivos das ocupações das escolas públicas secundárias do Rio de Janeiro em 2016», Forum Sociológico [Online], 32 | 2018, posto online no dia 16 julho 2018, consultado o 29 março 2022. URL: http://journals.openedition.org/sociologico/2019; DOI: https://doi.org/10.4000/sociologico.2019 


\title{
A ESCOLA COMO DEMANDA SOCIAL COMPLEXA: ENVOLVIMENTOS ESCOLARES E MOTIVOS DAS OCUPAÇÕES DAS ESCOLAS PÚBLICAS SECUNDÁRIAS DO RIO DE JANEIRO EM 2016
}

\section{SCHOOL AS A COMPLEX SOCIAL DEMAND: SCHOOL INVOLVEMENTS AND MOTIVES OF PUBLIC SECONDARY SCHOOLS OCCUPATIONS IN RIO DE JANEIRO IN 2016}

\author{
Ubirajara Santiago de Carvalho Pinto \\ Programa de Pós-Graduação em Sociologia Política (PPGSP), Universidade Estadual do Norte Fluminense (UENF), \\ Brasil
}

\begin{abstract}
Resumo
O artigo analisa os envolvimentos escolares e os sentidos de injustiça à volta da escola a partir de uma pesquisa de terreno nas ocupações das escolas públicas secundárias do Rio de Janeiro no primeiro semestre de 2016. Para tanto, procura-se explicitar o vocabulário de motivos das ocupações das escolas e discutir a complexidade da demanda pelo bem educacional à luz dos múltiplos envolvimentos na escola e seus significados plurais.
\end{abstract}

Palavras-chave: ocupações, sentidos de injustiça, escola e envolvimentos

\begin{abstract}
The article analyzes the school involvements and the meanings of injustice around the school from a fieldwork in the occupations of secondary public schools in Rio de Janeiro in the first semester of 2016. In order to do so, the aim is to make explicit the vocabulary of motives of public schools occupations and to discuss the complexity of the demand for the educational good in the light of the multiple involvements in the school and its plural meanings.
\end{abstract}

Keywords: occupations, senses of injustice, school and involvements

As ocupações das escolas públicas secundárias do Rio de Janeiro em 2016

O estado do Rio de Janeiro possui aproximadamente 1300 escolas públicas secundárias, das quais cerca de 80 foram ocupadas, no quadro de uma greve do magistério estadual que durou cinco meses: de março a julho de 2016. As razões da greve podem ser assim resumidas: o atraso sucessivo nos salários dos servidores do Estado, demissões dos funcionários terceirizados e, de um modo mais geral, a degradação das condições de trabalho no magistério estadual, no que tange à valorização das carreiras e no que se refere às condições de funcionamento mínimo das escolas.
As ocupações das escolas estaduais do Rio de Janeiro sucederam entre março e junho de $2016^{1}$. As manifestações em Macaé, principal foco desta investigação, tiveram início com a ocupação da escola Matias Neto no dia 5 de abril ${ }^{2}$. Nas semanas sequentes, são ocupadas as escolas Luiz Reid e, depois, a Vanilde Natalino Mattos. Neste artigo, faço análises exploratórias de registros realizados nestas três escolas e numa quarta, a escola Jamil El Jaick, situada em Nova Friburgo, cidade próxima a Macaé. Os dados integram um conjunto mais amplo de registros obtidos em trabalho de terreno entre abril e meados de outubro de 2016.

O início das ocupações, com os estudantes passando ao controle e monitoramento dos espaços 
da escola, faz-se anteceder por Assembleias. Os presentes manifestam suas razões e votam a proposta de ocupação. Com raras exceções, os primeiros dias de ocupação não encontram resistência das direções das escolas, com alguma participação de servidores, professores e alunos contrários.

Embora as ocupações tenham sucedido durante a greve do magistério, a baixa presença de professores nas ocupações e as dinâmicas de apoio recíproco entre estudantes e professores permitem dizer que a greve e as ocupações reúnem públicos distintos. Por outro lado, houve atos públicos com confluência de estudantes e professores e é possível identificar denúncias - por exemplo, das condições laborais dos professores e dos problemas de gestão das escolas - convergentes entre as ocupações, o sindicato e os professores em greve.

A frequentação às escolas ocupadas permitiu-me perceber que os professores não se reconheciam nas ocupações: sua participação isonômica e presencial era a exceção. Com efeito, houve participações diferenciais dos professores: os mais frequentes ligavam-se, em geral, à militância sindical ou a organizações partidárias de esquerda. Predominou, entre eles, a participação episódica, pela via de oficinas e aulas, ou mediante doações. As ocupações eram também apoiadas pelo sindicato dos professores e, por vezes, tinham a participação de militantes políticos de esquerda e/ou de entidades estudantis. A participação das famílias é pouco observada. Poucos pais apresentavam-se nestes espaços e muitos, à distância, eram contrários às mobilizações.

As ocupações são constituídas por públicos de composição variada, não propriamente no que se refere ao pertencimento de classe. Nas escolas aqui focadas predominam jovens dos meios populares, residentes, em geral, em bairros da periferia da cidade, com presença menos significativa de frações das classes médias baixas. Os públicos presencialmente implicados nas próprias ocupações são composições peculiares a cada escola.

Na escola Matias Neto havia uma composição de alunos da escola, amigos de alunos, militantes do PSTU e do sindicato e uma professora da escola também do PSTU ${ }^{3}$. Na escola Luiz Reid, predominavam alunos da escola, ex-alunos e amigos, com a presença pontual de poucos professores da escola em atividades culturais ou instrutivas na ocupação. Nessas escolas, durante a coabitação, dormiam entre 7 e 15 pessoas, chegando, em momentos tônicos, a pouco mais de 25 pessoas. Já na escola Vanilde havia alunos e seus amigos, com o suporte de uns poucos professores que não dormiam na escola: de menor porte, lá dormiam entre 5 e 10 pessoas. Por sua vez, na escola Jamil El Jaick, revezavam-se cerca de 10 alunos, com a participação próxima de alguns professores da escola, havendo sempre um professor a dormir. Em geral, predominam jovens entre 15 e 20 anos, de ambos os sexos, com presença notável, nas três escolas de Macaé, de jovens assumidamente LGBT na vocalização das críticas à situação das escolas e na organização das atividades. Em eventos voltados ao público alargado, tais como saraus, aulões, oficinas e festas, o número de pessoas aumentava.

O objetivo central do artigo é mostrar que a escola é uma demanda (de participação) social complexa. Para tanto, passa-se por dois eixos analíticos: a reconstituição mínima do vocabulário de motivos das ocupações (Trom, 2001) e a explicitação dos envolvimentos plurais (Thévenot, 2006) geridos na arena pública/proximal escolar e seus significados para o reconhecimento dos seres que coabitam a escola (Resende e Gouveia, 2013).

Primeiro, exponho o quadro teórico e os principais conceitos usados na análise e na organização dos dados da pesquisa. Em seguida, apresento os métodos de obtenção dos dados à luz das questões epistêmicas e das condições de realização da pesquisa de terreno. Ato contínuo, analiso alguns relatos de pessoas envolvidas nas ocupações, sobretudo jovens/ /estudantes, no sentido de explicitar o vocabulário de motivos das ocupações e os significados que os atores evocam para qualificar as (in)justiças, o (não) reconhecimento, os envolvimentos e as diferentes competências relacionais constitutivas da instável "comunidade escolar". Na conclusão, retomo as consequências das análises para o entendimento da escola enquanto ambiente de participação complexo, reforçando a pertinência reflexiva das contribuições diferenciais, das tensões e das avaliações plurais para o estudo das dinâmicas de socialização escolar contemporâneas.

\section{Como se mobilizam os ocupantes das escolas?}

Em De la justification, Boltanski e Thévenot (1991) propõem um quadro teórico para o estudo das operações críticas realizadas pelos atores nas situações cotidianas de conflito, denúncia e controvérsia. Na base do modelo coloca-se um princípio de "humanidade comum", que estabelece limites morais aos formatos da crítica, excluindo a violência e remetendo a "ordens de justificação" legítimas. A "ordem social" e os próprios acordos produzidos pelos atores nas situações de controvérsia não podem resultar da mera aparência de legitimidade: os próprios atores sabem discernir argumentos legítimos daqueles que não o são (Boltanski e Thévenot, 1991). Alegações incompatíveis com usos públicos são facilmente desacreditadas na arena pública (Cefaï, 2002).

A construção possível de um compromisso de critérios de justiça não depende da existência de 
uma "estrutura social" que previamente determina, pela internalização de expectativas normativas, quais os modelos de justificação mobilizados nas situações de conflito. As situações circunstanciadas e os atores, dotados de capacidades e competências cognitivas, possuem autonomia em relação aos princípios culturais e sociais que permeiam a sociedade mais ampla. O curso das situações não permite postular de antemão como se conformam os acordos ou desacordos e nem aquilo "de que as pessoas são capazes" (Boltanski, 1992).

A arena pública escolar já dispõe de apoios convencionais e gramáticas de vida pública (Cefaï, 2002; Dodier, 1993). Nela, os atores exercitam suas competências críticas, qualificam as situações, os seres e os objetos implicados. Neste sentido, a análise volta-se às competências gramaticais de que dão prova os atores em suas operações críticas, tomando a mobilização social como uma prova de publicização (Boltanski e Thévenot, 1991).

Esse modelo de competência moral e cognitiva apoia-se "igualmente sobre uma análise do agenciamento das situações nas quais as pessoas são levadas a realizar operações de crítica ou de justificação, sobre os dispositivos situacionais e sobre os objetos que compõem esses dispositivos" (Boltanski, 1992, p. 70). Ele integra seis "ordens de grandeza" e visa clarificar os princípios de justiça em que as pessoas se apoiam nas atividades críticas e as operações pelas quais elas assentam os méritos de suas asserções relacionando-as por meio de provas (Boltanski, 1992).

Como se verá, nos quadros de justiça mobilizados pelos atores para justificarem ou confrontarem as próprias ocupações aparecem quatro das seis cités ${ }^{4}$. Cada cité corresponde a um "valor geral e impessoal" com base no qual, em situações de disputa, os atores fundamentam suas pretensões de justiça em vista de um possível acordo. As cités são entendidas como "ordens de justificação" e "expressões do bem comum" a que os indivíduos se referem quando envolvidos em regime de justificação e encontram-se expressas em repertórios de vocabulários, objetos e etc. (Boltanski e Thévenot, 1991).

Durante as ocupações, a escola (e seu conjunto de relações e formas) é submetida a uma prova: ela é amplamente qualificada relativamente aos problemas mais gerais de justiça e aos envolvimentos que a constituem. Esses últimos são aqui analisados a partir da sociologia dos envolvimentos de Thévenot (2006) e de outras pesquisas que mostram a importância da amizade e das relações proximais na escola e para as identidades juvenis (Breviglieri, 2014; Resende e Gouveia, 2013; Thévenot, 2006).

As ocupações favorecem a obtenção de registros que permitem analisar os conflitos, os dilemas e os diferentes envolvimentos do cotidiano escolar. Seus públicos evocam uma série de outros acontecimentos pertinentes às artes de fazer o comum na escola (Resende e Gouveia, 2013). O conceito de múltiplos envolvimentos (Thévenot, 2006) alarga a análise das situações que não se prendem unicamente às exigências de justificação. Outros formatos de avaliação e envolvimento no/com o ambiente circundante têm consequências para a convivência, o tratamento e o reconhecimento dos atores nas situações por eles vivenciadas (Honneth, 2003; Resende e Gouveia, 2013; Thévenot, 2007).

Além do regime de justificação há outros envolvimentos: em plano, em familiaridade, em amizade. As dinâmicas efetivo-objetivas das situações trazem combinações e passagens entre os envolvimentos, que não são descritos como tipos ideais. Uma forma de caracterizar, sumariamente, a sociologia dos envolvimentos é dizer que a ação depende do ambiente e da situação para que seja bem-sucedida (Thévenot, 2006). A ação em plano requer apoios convencionais a sua execução, de modo que, por exemplo, a confecção de um diploma ou de um histórico escolar pode ser frustrada por eventos que interfiram na realização do plano. Dessa ação habitual ou normal pode-se passar a uma disputa por termos de justiça: basta pensar nas consequências para a progressão escolar ou para uma oportunidade de trabalho.

O envolvimento familiar, por seu turno, rege-se por significados ininteligíveis a observadores não familiarizados, e passa pela personalização do uso dos objetos e pela proximidade dos seres em jogo (Thévenot, 2006). Estende-se à familiarização com o espaço e às pessoas que convivem num ambiente: uma de suas formas possíveis na escola é a amizade, a qual conjuga a reciprocidade em justiça, o afeto e a proximidade (Boltanski, 1992; Resende e Gouveia, 2013).

Nessa perspectiva, faz-se uma análise exploratória de registros recolhidos nas quatro escolas mencionadas. A escolha do material ressalta de sua pertinência às duas categorias analíticas centrais a esta investigação - os quadros de justiça e os múltiplos envolvimentos na ocupação e na escola - e ao seu potencial reflexivo acerca dos critérios de justiça pertinentes a uma reflexão bem fundada da justiça escolar nas sociedades contemporâneas, particularmente no Rio de Janeiro.

A escolha das ocupações observou uma série de constrangimentos: epistêmicos, de acesso aos ambientes da ação e dos limites implicados na observação continuada. No plano epistêmico, era imperioso seguir os públicos em seus envolvimentos, a fim de reconstituir o espaço crítico em seus termos e as formas como os atores categorizam e qualificam a sua experiência.

Essa razão epistêmica fez-me ir à escola Matias Neto, a primeira ocupada em Macaé, pois dispunha do contato de um amigo militante do PSTU. Porém, 
minha presença na ocupação gerou alguma desconfiança e incômodo, em parte pelas perguntas que fiz, em parte por haver, entre os militantes do PSTU, uma familiaridade e uma disputa pelo espaço de suas ideias. $O$ acesso limitado às atividades "internas" desta ocupação e a relação que se configurou me fizeram decidir pela mudança de escola, para também ampliar o conjunto dos registros.

Passo à escola Luiz Reid, ocupada na sequência. Participar desde o início facilitou a aproximação com os jovens e o acesso aos eventos, sendo considerado, ao final, parte da "família Luiz Reid". Dessa escola, acessei as atividades das demais escolas de Macaé, havendo trânsito de pessoas e informações entre elas.

A realização de registros no decorrer da "ação coletiva" precisa curvar-se às exigências das atividades em jogo. Assim, muitos relatos das escolas Vanilde e Jamil foram obtidos através de grupos focais, ao passo que na Matias Neto fiz registros escritos e algumas gravações, enquanto na Luiz Reid gravei voz durante quase toda estadia. Toda atividade de terreno foi precedida dos esclarecimentos sobre sua finalidade e uso estritamente científico das informações, obtendo-se autorização junto aos públicos para a realização dos registros e resguardando-se, mediante pseudônimo, o anonimato e o sigilo das identidades.

Não obstante tenha feito um conjunto de registros em diversas ocupações e fóruns estudantis/ /juvenis, circunscrevi a análise ao material das quatro escolas com base em três razões: a primazia do monitoramento situado em vista do caráter temporal da "ação coletiva" (Cefaï, 2007), a ancoragem destas arenas em relações de proximidade e a urgência de conseguir inserção em campo, dada a incerteza sobre a duração das ocupações.

A frequência às escolas foi desigual, em razão da simultaneidade dos protestos. O recorte do material aqui analisado baseia-se na recorrência dos quadros de justiça e da dinâmica plural dos envolvimentos nas ocupações e nas situações escolares reportadas, compatibilizando-se com os eixos analíticos do artigo.

\section{A escola como bem comum plural: O vocabulário de motivos das ocupações}

Doravante analisa-se alguns relatos de jovens, estudantes e professores que estiveram nas ocupações. Inicia-se pelos sentidos de (in)justiça revelados no exercício das competências críticas e dos envolvimentos dos públicos. Explicita-se, a partir do quadro teórico, a coerência interna das justificações dos atores nas situações de altercação ou de qualificação dos envolvimentos. Alguns relatos de alunos das escolas Matias Neto e Luiz Reid permitem sintetizar as composições críticas recorrentes e o vocabulário de motivos das ocupações.
Porque a gente entende que a galera precisa realmente passar, só que pra vir pra escola e ter duas aulas de português igual estava tendo antes, não realmente não tinha como, porque na hora do ENEM a gente não vai ter só matéria de português. [...] teve uma reunião no comando de ocupações no Rio de Janeiro, e nessa reunião a gente conheceu outras escolas que também estão ocupando, e ouvimos as estórias que elas tinham pra contar! Cara, são cada coisa, são... coisas tão horriveis que estão acontecendo no ensino, e a gente pensa, poxa, só no Matias Neto, mas só que não é só aqui, é o Estado inteiro que tá passando por precarização, e é uma precarização imensa! São... falta de professores, falta de alimentação, falta de higiene, falta porteiro, falta de muita coisa... A gente entende que a gente precisa ter aula, todo mundo aqui quer ter aula, eu, por exemplo, eu não quero que... eu tenha cinco anos de ensino médio. Porém, os alunos não podem também ter todos os três anos completos, sendo três anos de aula precária, sem condições nenhumas, com aquele ensino baixo, e competir depois no ENEM com alunos de uma escola privada, que vai ter bem mais aulas que a gente, aulas bem melhores que a gente, eh, acho injusto falar que a gente tem que competir com este tipo de pessoa. E eu queria que vocês entendessem, o pessoal que é contra, e que viessem nas diversas reuniões que a gente faz, porque a gente tem palestra, não é só palestra sobre ensino, mas é também sobre cidadania [...]. (Ana, aluna da escola Matias Neto, 17 anos, 8 de abril, 2016)

Ana responde a um posicionamento contrário à ocupação, em que se solicita a realização de um curso preparatório às provas do ENEM, que classificam para o ingresso nas universidades ${ }^{5}$. Na fala de Ana há pelo menos três princípios gerais de justiça que qualificam a escola como bem comum: sua eficácia industrial, seu valor cívico, na medida em que se trata de defender a escola em solidariedade à greve dos professores, e um certo desarranjo doméstico captável em "não é só aqui" e naquilo que "falta", entre insumos e pessoas que desempenham diferentes papéis na ordenação da escola. Um quarto princípio, o modelo inspirado do saber e da criatividade, enuncia-se apenas vagamente. Não detalho aqui os critérios avocados contra as ocupações, pois operam nos mesmos quadros de sua justificação, mas reclamam seu uso habitual e a continuidade do calendário, enfatizando as dimensões cívica e industrial. Na mesma Assembleia, diz Fênix:

[...] a gente está lutando por um direito que é nosso, quando chegar no final do ano 
- Estado vai querer passar todo mundo, eu sou do $1 .^{\circ}$ ano, eu não vou querer passar sem saber, como você que está no $3 .^{\circ}$ ano não vai querer passar sem saber. E como a gente tava falando mais cedo, a gente não tem que pensar só na gente, mas tem a minha memória também, como a minha vó estudou nesta escola eu também estudei, e os filhos de vocês vão querer estudar, você vai querer que seu filho e a sua filha tenham esse direito? Você também vai perder... [...] Estamos lutando por uma coisa que realmente é nossa, entendeu, é um direito nosso lutar pelo nosso direito. Você paga imposto, eu pago imposto, pra ter um ensino de qualidade, entendeu, não pra você vir pra escola e ter duas aulas. [...] É a nossa decisão, claro que nós também vamos respeitar a de vocês. Cada um tem que opinar, entendeu, cada um tem as suas escolhas. (Fênix, aluno da escola Luiz Reid, 17 anos, 8 de abril, 2016)

A argumentação de Fênix traz uma composição de critérios de justiça: 1) o modelo de justificação inspirado, expresso na ideia do saber por ele mesmo; 2) o sentido industrial, que fornece o idioma da crítica à qualidade do ensino; 3) o modelo de justificação doméstico, que remete à família e às relações "nesta escola"; e, por fim, 4) o sentido cívico de "lutar pelo nosso direito" (Boltanski e Thévenot, 1991). A crítica cívica comporta também a denúncia do "autoritarismo" das direções. Uma das pautas das ocupações e do sindicato dos professores é a eleição para a direção. Os alunos criticam a inépcia relacional dos diretores e de alguns professores, que não sabem lidar com a "grandeza inspirada" dos estudantes, com seus projetos criativos e sua projeção cívica na ordem doméstica escolar (Thévenot, 1986). Nota-se a tensão entre a simetria cívica e a "grandeza doméstica" dos mais experimentados na precedência dada aos professores e à escola como instituição hierarquicamente regida pelos mais experimentados.

Em suma, eis o vocabulário de motivos das ocupações das escolas: 1) cívico, no sentido da igualdade, da solidariedade, do déficit de preparação escolar em garantir a continuidade dos estudos, dos projetos de autonomia e da igualdade de oportunidades; 2) doméstico, na medida em que a escola é também o universo de relações pessoais e de hierarquia, além das implicações dos diferentes graus de "experiência" temporal e classificatória escolar; 3) industrial, já que a qualificação deve ter eficácia, havendo uma pletora de objetos desajustados aos quais se apegam os atores para fazer essa crítica; 4) inspirada, com o reconhecimento da escola como lugar do saber e da criação artística para além de qualquer sentido instrumental (Boltanski e Thévenot, 1991); e 5) a ideia de livre associação/expressão que, a despeito de seu sentido de justiça, apoia-se nos critérios anteriormente citados.

Neste quadro, no dia 22/04/2016, Gaia sintetiza os motivos das ocupações, ao mesmo tempo que qualifica a escola como um espaço fundamental ao alargamento da experiência juvenil em direção à autonomia e à grandeza pública (Breviglieri, 2007).

É uma preparação para fora, porque a escola... eu vejo o papel da escola como uma segunda, como uma segunda... Eu vejo a escola como um plano $B$ de casa. Na casa nós temos a educação, na escola a instrução. Então é educação e instrução, elas se parecem, mas tem uma diferença e, aqui no colégio, a gente aprende, a gente sai de casa e começa a viver com outras pessoas desde pequeno. Então a gente começa a ter aquele aprendizado social.

$E$ isso é uma coisa que ao longo dos anos a gente vai vendo que a escola perdeu esse papel de ensinar a gente a viver aqui fora. Eu vejo essa ocupação e todas essas manifestações como um regresso disso.

(...) Se estudava dentro de casa. Isso há muito tempo atrás. As coisas foram mudando e só quem tinha dinheiro ia para a escola. E homens, que todo mundo sabe. Mas a gente tem que voltar no tempo para lembrar e para entender o que está acontecendo hoje. Quando começamos a chegar na escola... que educação vem de casa. Aqui, você chegava tinha palmatória, educação tradicional e não sei o quê. Era mais rígido, então você não precisava criar laços com o seu aluno porque você estava ali para ensinar. Porque a educação vinha de casa. O tempo passa, a sociedade muda, o estudo muda. [...] a escola agora, os professores têm o dever de educar e ensinar. Educar no sentido de vida. [...] ensinar adolescente a viver, a criança a viver, a andar com as próprias pernas. Porque a família não tem mais tempo para isso. Os pais trabalham em dois empregos, a mãe trabalha e todo mundo fica o dia inteiro fora de casa e é isso aí. (Gaia, aluna da escola Luiz Reid, 20 anos, 25 de abril, 2016)

Essa crítica dirige-se à deficiência do programa de socialização escolar, ressaltando seu dever de preparação dos jovens para a autonomia. Tal preparação implica uma difícil composição de envolvimentos no quadro do compromisso com os critérios de justiça acima enumerados. Gaia expõe, ademais, a "fragilidade das identidades juvenis", pois revela sua condição de menoridade relativamente ao estado canônico da autonomia, identificada ao mundo adulto e à grandeza cívica (Breviglieri e Stavo-Debauge, 2004). Por outro lado, 
a universalidade das experiências proximais na escola, vitais às sucessivas provações pelas quais o jovem "deve" amadurecer, remete à importância dos laços de proximidade entre as formas plurais do bem comum escolar (Resende, Caetano e Dionísio, 2017; Resende e Gouveia, 2013).

\section{A escola, outros bens, envolvimentos e significados}

Como ficou dito, os envolvimentos em proximidade também apontam para (in)justiças relacionadas à participação na ordem doméstica da escola. (Resende, Caetano e Dionísio, 2017). Os jovens relatam experiências que já fazem parte dos regimes de ação que constituem a escola, mas que são invisibilizados (Rayou, 2007; Resende e Gouveia, 2013). Tais experiências mostram a complexidade das demandas reportadas à escola pública e os significados que ela pode vir a assumir nas diferentes trajetórias escolares, que podem ser atravessadas por provações de ordem íntima ou familiar, assim como por projetos de variado teor (Boltanski e Chiapello, 2011) e não são, destarte, meros efeitos de uma estrutura de relações posta.

As questões da família e da casa conectam-se - para os públicos dos estratos sociais que frequentam as escolas públicas que temos por foco - com frequência com a ideia de um acolhimento que se espera da escola, reportado nos significados que das sociações escolares, para além da instrução pelo modelo da autoridade e dos resultados.

É de se ressaltar, nas lógicas de ação e nos significados evocados pelos alunos à volta da escola, o valor da convivência para o aprendizado. Na escola Vanilde, disseram alguns alunos:

[...] a gente deveria ter mais coisas para fazer na escola. Achar que a escola é a nossa segunda casa não é um bicho de sete cabeças.

[...] acho que a escola precisa abraçar mais os alunos, não ficar esperando só que a gente venha, faça toda a nossa rotina e que a gente vá embora.

[...] a gente chega é quadro até dar a hora e, depois, a gente vai para a casa. A única diversão é sair no horário do lanche e conversar um pouco com os amigos que são de outra sala. (Grupo focal, alunos da escola Vanilde, Diana, 17 anos, Ávila, 16 anos, e Alexia, 16 anos, 18 de maio, 2016)

Os envolvimentos nas ocupações e as narrativas do cotidiano escolar apontam para experiências significativas na escola, a despeito de sua intensa qualificação crítica. Os alunos avaliam os envolvimentos com a escola por meio das ideias de afeto, amizade, proximidade e convivência.
Assim, da minha turma tem uns 35, mais ou menos. Aí uns 15 já saíram. Só que deixaram um recado, se as aulas do Jamil voltarem, voltam para lá. Porque querem finalizar junto com os alunos, os amigos, os professores.

Porque são 3 anos juntos. A maioria vem para cá tudo no $1.0^{\circ}$ ano.

O pessoal gosta da escola, entendeu?

É família.

Dos funcionários, da direção. Alguns não concordam com a direção, outros são a favor... (Grupo focal, alunos da escola Jamil El Jaick, Jean, 16 anos, Teodoro, 17 anos, e Arquimedes, 17 anos, 30 de maio, 2016)

Assim, os sentidos da escola mostram que ela comporta interações plurais significativas. É o que também se depreende do relato de Camille, no dia $19 / 05 / 2016$, acerca de seu envolvimento escolar.

- Por que especificamente dessa?

- [...] E eu era bem introvertida, então, isso não me ajudou muito. E quando eu vim pra cá, eu cresci bastante. Tanto por uma quantidade muito grande de pessoas, quanto por uma infinidade de pensamentos e ações diferentes e ideias e ideologias, e eu conheci muita gente diferente. Essa escola me proporcionou isso. E quando eu vim pra Macaé tinha, na verdade, não tinha nem um ano que o meu pai tinha falecido, tinha sete meses e eu tinha, tipo, dez anos. E o único lugar que eu conseguia me sentir, digamos, melhor, de todo o tempo que eu estava aqui, que eu acho que já tinha 3 anos, foi aqui no Luiz Reid. E tipo eu conheci pessoas que são meus amigos até hoje. A minha melhor amiga eu conheci por causa do Luiz Reid, não porque ela estudava aqui, mas ela vinha aqui porque tinha outras amigas aqui, e se eu não estudasse aqui eu nunca teria conhecido ela. E eu realmente acabei fazendo muitas amizades e muitas pessoas que me ajudam até hoje, muitas pessoas que eu sei que tão comigo. (Camille, ex-aluna da escola Luiz Reid, 19 anos, 19 de maio, 2016)

Camille aponta para laços políticos e envolvimentos em proximidade e qualifica as interações escolares mediante as palavras ajudar, amizade, convivência, diferença e conhecer. Na sequência, ela relata uma manifestação que os alunos fizeram em oposição à ação da diretora, que pretendia retirar um senhor chamado Sassá do quarto em que, na escola Luiz Reid, residia.

[...] Ah, tudo bem, ela tem direito de fazer isso à vontade, ninguém está reclamando disso. Só que, por exemplo, o Sassá mora 
aqui e, tipo, ela dava uma marmita com uma quantidade muito pouca de comida pra ele. Ele dormia num local muito sujo. E, tipo, foda-se sabe? [...]. Ele tá aqui, eu não sou obrigada a cuidar dele, mas já que eu tenho que cuidar dele eu vou dar tipo o mínimo pra ele. [...] $\mathrm{E}$ já que ele mora aqui, porque não cuidar dele direito? E fora que, por exemplo, os cachorros cuidam mais da escola do que ela, e eles são, tipo, mais respeitados do que ela, por exemplo. Se alguém tenta fazer alguma coisa com o Sassá eles começam a latir. Tipo, vão pra cima, por exemplo. Ou então se alguém começar a brigar aqui na escola, eu mesma já vi, sabe, por exemplo, os cachorros irem pra cima quando tinha tipo uma briga aqui na escola. (Camille, ex-aluna da escola Luiz Reid, 19 anos, 19 de maio, 2016)

No que tange a Sassá e à escola, tomando-os como metonímia do humano em geral, espera-se que seu tratamento seja feito de cuidados. Sassá "mora aqui" na Luiz Reid: ante sua condição vulnerável vê-se a importância de seu envolvimento familiar com a escola (Thévenot, 2006). Esses múltiplos envolvimentos, que ressaltam dos relatos, mostram, igualmente, tensões na conformação da "comunidade escolar". Por outro lado, observa-se, no itinerário de Camille, a importância afetiva da escola num período de problemas íntimos e familiares e a interferência destas questões no seu envolvimento escolar.

[...] Só que depois que eu vim pra cá eu acabei tendo muitos problemas pessoais, tipo na minha família. Não por causa daqui, mas, por exemplo, tipo... [...] Isso influenciou bastante no fato de eu ter repetido. Só que eu fiz uma escolha. Tipo, eu não conseguia ir pra aula, porque eu não estava bem mentalmente pra ir pra aula. Então eu fiz uma escolha: eu não vou. Eu vou repetir por falta, eu vou repetir por nota e eu não vou. (Camille, ex-aluna da escola Luiz Reid, 19 anos, 19 de maio, 2016).

\section{A escola e outros bens: A eficácia, o saber e o mundo do trabalho}

A interrupção das aulas, nos períodos de greve, gera divisões internas aos públicos escolares: entre docentes e, sobretudo, entre os discentes que dependem da continuidade do calendário letivo para completar sua qualificação escolar. Um dos focos da crítica nas ocupações diz respeito à ineficácia das aulas, que resulta em desvantagens competitivas na qualificação escolar e no comprometimento da dimensão do saber.
O ano passado, por exemplo, eu fiquei sem aula de história praticamente o ano todo. Eu não sei o motivo. [...] Ou seja, eu passei sem saber nada. [...] Eu tenho uma professora que é de matemática, de física, é de tudo. E não só na minha sala. Ela ensina a gente para a gente não ficar sem saber. E ela ensina várias coisas ao mesmo tempo. (Ávila, aluna da escola Vanilde Mattos, 16 anos, 23 de maio, 2016)

Os relatos mostram que a necessidade prematura do trabalho - comum entre muitos alunos das escolas estaduais - interfere na dinâmica dos envolvimentos e na eficácia escolar:

\footnotetext{
Diana: - São 7 salas. São 6 salas. Algumas têm bastante gente. Ávila: - A gente até colocou na nossa pauta ter no mínimo 25 alunos por sala de aula. Porque tem sala tão vazia à tarde. Diana: - O período da tarde é tranquilo. Ávila: - Porque existe uma grande demanda da pessoa estudar de manhã para poder trabalhar à tarde, as salas ficam superlotadas. (Alunas da escola Vanilde, Diana, 17 anos, e Ávila, 16 anos, 23 de maio, 2016)
}

A necessidade do trabalho contribui para complexificar a demanda pela escolarização e interfere na qualidade dos envolvimentos escolares, nas significações e nas implicações que a interrupção da escolarização pode ter sobre os projetos de diferentes alunos. É o que também diz a professora Luna:

[...] A turma de manhã e de tarde, eu acho super tranquila de lidar. Até porque eu acho que são os alunos que estão no período regular mesmo, geralmente não trabalham, então eles estão só para vivenciar a escola. À noite muitos trabalham. Às vezes, estão até no período regular, sim. Regular que eu falo é: não saiu do colégio, não foi reprovado. Estão naquela faixa que a escola diz como normal, sim. Eram para estar naquele ano. $E$ muitos trabalham, então, estão cansados. Outros já repetiram várias vezes. Muitos vêm para escola e veem a escola como algo que eles nem se identificam. Nem eles sabem porque estão aqui. (Luna, professora na escola Luiz Reid, 24 de abril, 2016)

Neste passo, a escola como demanda social complexa pode ser remetida a dois conjuntos de questões. O primeiro diz respeito à dimensão socioeconômica, que se traduz em diferentes condições sociais de experimentação e disputa pelo bem público escolar. $O$ segundo conjunto de questões, mais próximo da abordagem qualitativa desta pesquisa, combina-se com o primeiro, mas merece 
tratamento específico, na medida em que se abre pragmaticamente às diferentes formas pelas quais os públicos escolares envolvem-se com a escola e a significam (Derouet, 2010).

Os significados da escola não se reduzem à dimensão da eficácia puramente industrial/meritocrática. Este sentido vai de par com outras demandas de significação da socialização escolar, as quais se voltam à qualidade das relações que se dão na escola, especificando-as de várias formas: amizade, convivência, reconhecimento, respeito e, quanto mais difíceis as condições do envolvimento escolar, cuidados, afeto, escuta e acolhimento (Resende, 2010; Resende e Gouveia, 2013).

As condições de envolvimento com a escola, além das condições sociais, não são garantias acabadas de uma vez por todas (Ricœur, 2001) e podem ser perturbadas por dilemas nas relações familiares, na esfera econômica, íntima ou em relações sociais deceptivas em outros espaços. A própria escola, enquanto tessitura cotidiana de envolvimentos, é afetada por outros dispositivos de socialização e suas exigências variadas à individuação e à subjetivação que, na vida dos diferentes seres, assumem diferentes combinações possíveis com o plano da conformidade à socialização escolar (Caetano, 2013).

\section{A complexidade da demanda e dos envolvimentos escolares}

O artigo procura mostrar, ao examinar as razões de primeiro plano e os envolvimentos escolares a partir das ocupações de quatro escolas do estado do Rio de Janeiro, a complexidade da demanda (de participação) na escola. A composição plural de critérios de justiça na crítica às condições da oferta escolar já aponta para a complexidade deste bem público. As evidências de que a escola comporta outras socialidades e competências relacionais fundamentais ao alargamento da experiência juvenil em direção à autonomia e à grandeza pública (Breviglieri, 2007) traz à reflexão elementos que reforçam o argumento de que se trata de uma demanda social complexa: não se pode arredar dela a multiplicidade de lógicas de ação, suas tensões e composições (Resende e Gouveia, 2013). Essas lógicas podem colidir ou ser obliteradas nos próprios envolvimentos e os formatos de avaliação nem sempre são comensuráveis e/ou atentos à diversidade de bens e enquadramentos das situações escolares.

A socialização escolar exige a difícil composição de regimes de envolvimento. A escola é uma arena pública que implica a copresença, a proximidade e a realização de projetos individuais que importam ao reconhecimento dos seres que a coabitam. Os envolvimentos trazidos à luz na pesquisa revelam a complexidade da vivência escolar nas condições de socialização dos jovens das escolas secundárias do Rio de Janeiro. As artes de fazer o comum não se dão sem tensão, mal-entendidos, conflitos e experiências passíveis de serem percebidas pelos seres como (in)justas ou (des)ajustadas às figurações plurais da justiça escolar e ao reconhecimento de uns e outros (Resende e Gouveia, 2013).

\section{Notas}

1 Identifica-se três ciclos de ocupações: um em 2015 e dois outros ao longo de 2016.

2 Macaé tem 240 mil habitantes e fica ao norte do Rio de Janeiro.

3 Partido Socialista dos Trabalhadores Unificado.

4 O conceito de cité se refere a princípios morais que, dada sua universalidade e generalidade, podem facultar a ordenação política. São os quadros normativos em que se baseiam as críticas justificáveis (Boltanski e Thévenot, 1991).

5 ENEM é o Exame Nacional do Ensino Médio. Ensino médio ou secundário designam, no Brasil, o mesmo nível.

\section{Referências bibliográficas}

Boltanski, L. (1992). L'amour et la justice comme compétences. Trois essais de sociologie de l'action. Paris: Gallimard.

Boltanski, L., e Chiapello, È. (2011). Le nouvel esprit du capitalisme. Paris: Gallimard.

Boltanski, L., e Thévenot, L. (1991). De la justification. Les économies de la grandeur. Paris: Gallimard.

Breviglieri, M. (2007). L'arc expérientiel de I'adolescence: Esquive, combine, embrouille, carapace et étincelle... . Éducation et sociétés, 1(19), 99-113.

Breviglieri, M. (2014). La vie publique de I'enfant. Participations, 2(9), 97-123.

Breviglieri, M., e Stavo-Debauge, J. (2004). Les identités fragiles. La "jeunesse" et "I'immigration". In C. Vincenzo, C.-P. Catherine, \& R. Tariq (Eds.), Ce que nous savons des jeunes (pp. 159-176). Paris: PUF.

Caetano, P. (2013). Individuação e reconhecimento: Processos de socialização política na incerteza dos itinerários escolares (Tese de doutoramento). Universidade Nova de Lisboa, Faculdade de Ciências Sociais e Humanas, Lisboa, Portugal.

Cefaï, D. (2002). Qu'est-ce qu'une arène publique? Quelques pistes pour une approche pragmatiste. In D. Cefaï, \& I. Joseph (Eds.), L'héritage du pragmatisme (pp. 52-81). La Tour d'Aigues: Éditions de l'Aube.

Cefaï, D. (2007). Pourquoi se mobilise-t-on? Les théories de l'action collective. Paris: La Découverte.

Derouet, J.-L. (2010). Crise do projeto de democratização da educação e da formação ou crise de um modelo de democratização? Algumas reflexões a partir do caso francês (1980-2010). Educação \& Sociedade, 31(112), 1001-1027. 
Dodier, N. (1993). Les appuis conventionnels de l'action. Éléments de pragmatique sociologique. Réseaux, $11(62), 63-85$.

Honneth, A. (2003). Luta por reconhecimento: A gramática moral dos conflitos sociais. São Paulo: Editora 34

Rayou, P. (2007). De proche en proche, les compétences politiques des jeunes scolarisés. Éducation et sociétés, 1(19), 15-32.

Resende, J. (2010). A sociedade contra a escola? A socialização política escolar num contexto de incerteza. Lisboa: Instituto Piaget.

Resende, J., Caetano, P., e Dionísio, B. (2017). Das experiências de (des)qualificação das pessoas à precariedade dos laços entre os seres que habitam o mundo escolar. Dilemas. Revista de Estudos de Conflito e Controle Social, 7(1), 11-38.

Resende, J., e Gouveia, L. (2013). As artes de fazer o comum nos estabelecimentos de ensino: Outras aberturas sociológicas sobre os mundos escolares. Forum Sociológico, (23), 97-106.

Ricœur, P. (2001). Autonomie et vulnérabilité. Le juste, 2, 85-107.

Thévenot, L. (1986). Grandeur et misére de la jeunesse. La qualité de jeune dans les jugements de grandeur. In M. Perrot (Org.), Les jeunes et les autres. Contributions des sciences de l'homme à la question des jeunes (Vol. 1) (pp. 29-41). France: CRIV.

Thévenot, L. (2006). L'action au pluriel: Sociologie des régimes d'engagement. Paris: La Découverte.

Thévenot, L. (2007). Reconnaissances: Avec Paul Ricœur et Axel Honneth. In A. Caillé (Dir.), La quête de reconnaissance. Nouveau phénomène social total (pp. 269-283). Paris: La Découverte.

Trom, D. (2001). Grammaire de la mobilisation et vocabulaires de motifs. Raisons Pratiques, (12), 99-134.

Recebido a 31/08/2017. Aceite para publicação a 13/12/2017.

Ubirajara Santiago de Carvalho Pinto (santiagosamba@yahoo.com.br). Programa de Pós-Graduação em Sociologia Política (PPGSP), Universidade Estadual do Norte Fluminense (UENF). Av. Alberto Lamego, 2000 - Parque Califórnia, Campos dos Goytacazes, 28013-602 Rio de Janeiro-RJ, Brasil. 